\title{
Short-Term Measurement of Linear Growth in Preterm Infants: Validation of a Hand-Held Knemometer
}

\author{
KIM FLEISCHER MICHAELSEN, LISELOTTE SKOV, JENS HENRIK BADSBERG, AND \\ MERETE JØRGENSEN \\ Department of Human Nutrition, The Royal Veterinary and Agricultural University, Copenhagen [K.F.M.], \\ University Department of Growth and Reproduction, Rigshospitalet, Copenhagen [K.F.M.], University \\ Department of Pediatrics, Hvidovre Hospital, Copenhagen [L.S.], and Statistical Research Unit, University of \\ Copenhagen, Denmark [J.H.B., M.J.]
}

\begin{abstract}
A hand-held electronic knemometer, resembling a pair of callipers, for measuring knee-heel length in preterm infants was developed to improve the accuracy of measuring linear growth velocity in infants. The measuring system is based on a magnetic encoder and has a resolution of $0.01 \mathrm{~mm}$. The knee-heel length is recorded automatically when the pressure applied on the heel reaches a preset value. The result of a measurement sequence is expressed as the average of five sequential readings. The error of one measurement sequence was $0.82 \mathrm{~mm}$, corresponding to a coefficient of variation of $0.8 \%$ or $\mathbf{2} \mathrm{d}$ of growth in kneeheel length. It includes the technical error and an error component due to the correlation of the readings within a series. The estimated error on the measurement of the knee-heel growth velocity (expressed as $\mathrm{mm} / \mathrm{d}$ ), measured over a 3-wk period, was $0.04 \mathrm{~mm}$, corresponding to a coefficient of variation of $8 \%$. Longitudinal growth data from 11 healthy preterm infants (birth weight 918-1482 g) are presented. Knee-heel length velocity from birth until day of regained birth weight was similar to the velocity during the following weeks, showing that there was no deceleration of growth immediately after birth. In conclusion, the method is accurate and gentle in measuring linear growth velocity over short periods and can be useful in monitoring the progress of ill infants and in growth studies of preterm and mature infants, in which linear growth is a more relevant short-term outcome than weight gain. (Pediatr Res 30: 464-468, 1991)
\end{abstract}

\section{Abbreviations}

RBW, day of regained birth weight

Growth is one of the best indicators of well-being in infants. Assessment of growth in infants is mainly based on weight measurements, because weight can be obtained easily and with a high degree of reliability. As a single criterion of growth, however, measurement of length is regarded as a better criterion

Received October 4, 1990; accepted April 29, 1991

Correspondence and reprint requests: Kim Fleischer Michaelsen, Research Department of Human Nutrition, The Royal Veterinary and Agricultural University, Rolighedsvej 25, DK-1958 Frederiksberg C, Denmark.

The development of the knemometer was supported by a grant from Dr. Louises Børnehospitals Forskningsfond. During the study, K.F.M. was supported by grants from Otto Mønsteds Fond, the Danish Medical Research Council (12-5957, 12 7735), the Danish Technical Research Council (16-4338 H), and the Danish Natural Research Council (11-7011). than measurement of weight $(1,2)$, and it cannot be assumed that weight gain and linear growth are always correlated. Excessive fat deposition or water retention affect weight gain but not linear growth. Growth during early life is characterized by a large deposition of fat, and the rate of this deposition might be influenced by factors that do not influence linear growth. Excessive solute intake also results in large weight gain, without a corresponding increase in linear growth $(1,2)$.

Measurement of crown-heel length in infants is often too inaccurate to allow a precise assessment of short-term linear growth velocity, and the measuring procedure is not particularly gentle to the infants. Measurements of crown-heel length are often impossible in sick preterm infants, particularly when they are on artificial ventilation. There is, therefore, a need for an instrument to make accurate measurements of linear growth in preterm and mature infants gently and with ease.

The method of measuring the lower leg length with a special device, called a knemometer, was developed by Valk et al. (3), and knemometry has proven to be a powerful tool for measuring linear growth over short periods (4-6). Later, other more simple instruments for measuring knee-heel length were developed (79 ). Knee-heel length is preferred to the total height because it is more stable, including only one relatively fixed joint and, thus, allowing more accurate measurements. However, the existing instruments can only be used in children over $4-5 \mathrm{y}$, because the child must be seated and must cooperate during the measuring procedure.

Brooke $(10,11)$ has used measurements of knee-heel length in several studies of growth in preterm infants. The distance was measured with callipers to the nearest $\mathrm{mm}$. To our knowledge, the method's error has not been evaluated.

To improve the accuracy in measuring linear growth during early life, we have developed a hand-held electronic knemometer for use in preterm infants up to the age of $1 \mathrm{y}$.

The aim of this study was to describe the instrument and the measuring procedure and to evaluate the error when measuring knee-heel growth velocity. Furthermore, longitudinal growth data from healthy preterm infants are presented to compare linear growth and weight gain during the first weeks of life.

\section{MATERIALS AND METHODS}

Knemometer. The knemometer, developed in collaboration with the Danish Institute of Biomedical Engineering, resembles a pair of electronic callipers. It records the knee-heel length automatically when the pressure applied on the heel reaches a preset value. The measuring system, which is based on a magnetic encoder, has a digital read-out and a resolution of $0.01 \mathrm{~mm}$ (Fig. 1). The instrument can measure knee-heel lengths up to $24 \mathrm{~cm}$, 
which is sufficient to measure a 12 -mo-old infant. The measuring is done with the infant relaxed in the supine position. With $90^{\circ}$ flexion at both hip and knee, the left arm of the callipers is held against the infant's knee. The knee is supported with the fingers of the left hand, but not so tight that the knee cannot move when pressure is applied to the sole of the foot. The foot is placed on a plate on the right arm of the callipers, so that the anterior end of the tibia is parallel to the body of the callipers. The foot is then supported by the fingers in the same way as the knee, and increasing pressure is applied on the right arm of the callipers. The readings, which are recorded automatically when the pressure reaches $80 \mathrm{~g}$, are automatically transferred to a small printer/ computer for storage and calculation of simple statistics such as mean, $\mathrm{SD}$, and range.

The result is expressed as the mean of five readings taken sequentially as a series, and throughout this study a measurement represents such a mean. With the automatic recording, the observer is unaware of the results before the end of a series, and part of the observer bias is thereby eliminated. However, if the observer feels that an individual reading may be wrong, as for instance when the infant has been moving his or her leg, it is possible to cancel this reading from the series and replace it by a new reading before the next reading is entered. By evaluating the $\mathrm{SD}$ on the printout when a series has been completed, measurements with outlying readings, and thereby a large $\mathrm{SD}$, can be identified immediately and repeated if necessary. This was not done during the present reliability study, because we wanted to give a complete description of the possible errors.

Reliability study. To examine the measuring errors that occur when using the method, two observers independently measured five preterm infants daily for $4 \mathrm{~d}$. The two observers measured the same infant within $15 \mathrm{~min}$. One of the observers had used the knemometer for several months, while the other only had a few days' experience. Each measurement consisted of a series of five sequential readings. To estimate the error when measuring a phantom that cannot be deformed, an $11-\mathrm{cm}$ long metal cylinder was measured 20 times, each measurement consisting of five readings.

Growth study of healthy preterm infants. Eleven preterm infants, with a mean birth weight of $1248 \mathrm{~g}$ (range 918-1482 g), a mean gestational age of $29.7 \mathrm{wk}$ (range $27-33 \mathrm{wk}$ ), and no severe neonatal disease, were followed until they weighed 2000 g. Kneeheel length was measured on Mondays, Wednesdays, and Fridays throughout the study (there were daily measurements on five of the infants during the first $2 \mathrm{wk}$ ). A total of 256 measurements were performed by two observers (L.S., K.F.M.).

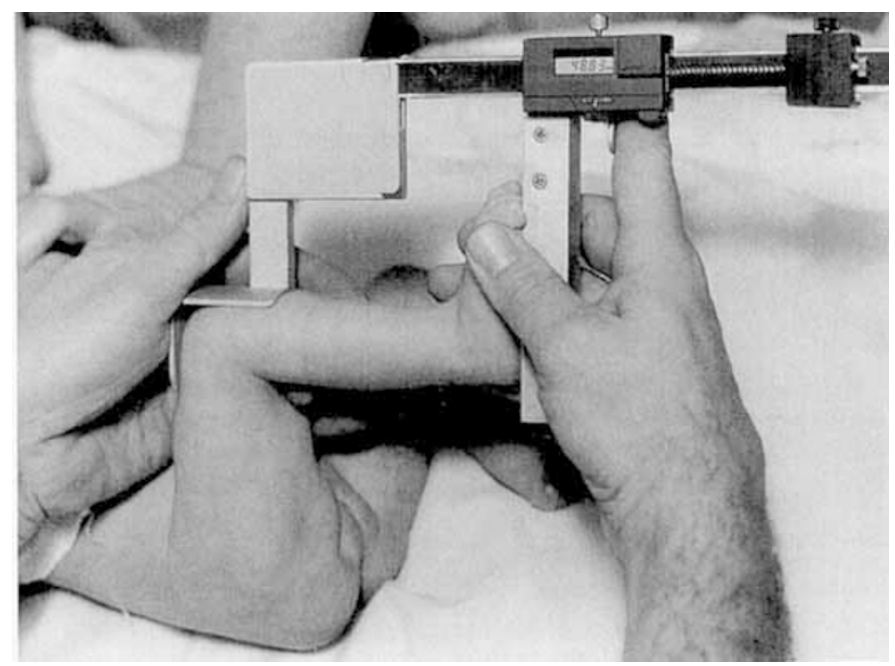

Fig. 1. Knee-heel length measured using the infant knemometer in a preterm infant.
The studies were approved by the local ethics committee and informed consent was obtained from the parents.

Statistical methods. Analysis of variance (12) was used to identify the significant sources of variation in the reliability study. A series of five knee-heel lengths (indexed by $j=1, \ldots, 5$ ) for infant (i), on day (d), measured by observer (o) could be described by the exact knee-heel length for infant (i) on day (d) plus an error component allowing for a positive correlation between measurements within the same series. In mathematical terms, the model is described by

$$
\mathrm{X}_{\text {idoj }}=\mu_{\mathrm{id}}+\mathrm{V}_{\mathrm{ido}}+\mathrm{U}_{\mathrm{idoj}}
$$

where $X_{\text {idoj }}$ denotes the $j$ th reading in a series of five of the kneeheel length for infant $i$, day $d$, and observer $o, \mu_{\text {id }}$ denotes the true knee-heel length, and $V_{\text {ido }}$ and $U_{\text {idoj }}$ denote the error term. $V_{\text {ido }}$ and $U_{\text {idoj }}$ are assumed to be independent, normally distributed random variables with a mean of zero and variance $\tau^{2}$ and $\sigma^{2}$, respectively.

The variance component $\sigma^{2}$ describes the variation within a series of readings and $\sigma$ corresponds to the technical error of measurements used in other studies $(4,5)$. The other variance component, $\tau^{2}$, describes the covariance between two readings within a series. This variance component includes the betweenobserver and the within-observer variation, which cannot be separated using the present study design. The standard error of one single reading in a series is $\sqrt{\tau^{2}+\sigma^{2}}$, and the standard error of one measurement (mean of five readings) is $\sqrt{\tau^{2}+\left(\sigma^{2} / 5\right)}$. The correlation between two readings within a series $\delta=\tau^{2} /\left(\tau^{2}+\sigma^{2}\right)$.

The standard error of the measurement of knee-heel growth velocity using different observation periods and measuring intervals was estimated using the following formula:

$$
\sqrt{\left[\tau^{2}+\left(\sigma^{2} / 5\right)\right] / \Sigma\left(t_{k}-\bar{t}\right)^{2}}
$$

where the sum is over all points in time of measurements $t_{k}$ and $\bar{t}$ denotes the mean of $t_{k}$.

Growth velocities (knee-heel length and weight) were calculated by linear regression (12) using all measurements during the observation period.

\section{RESULTS}

The statistical model used in the reliability study was obtained by successive reduction from a larger model allowing for systematic differences between observers and first order interaction between observer and infant and between observer and day. None of these additional interaction terms were significant, and in general there were no significant differences between the observers' measurements. The variance $\left(\sigma^{2}\right)$ was estimated to $1.52 \mathrm{~mm}^{2}$ and the covariance $\left(\tau^{2}\right)$ to $0.37 \mathrm{~mm}^{2}$. There was a significant correlation between the readings within a series $(r=$ $0.20, p=0.007$ ). Therefore, the standard error of one measurement (mean of five readings) was $0.82 \mathrm{~mm}$. Assuming a total knee-heel length of $100 \mathrm{~mm}$, this corresponds to a coefficient of variation of $0.8 \%$. The estimates of the growth velocities during the 4-d period for the five children (linear regression of kneeheel length on day for each child) were $0.37,0.51,0.83,1.00$, and $1.22 \mathrm{~mm} / \mathrm{d}$, with a standard error of $0.27 \mathrm{~mm} / \mathrm{d}$. The standard error of the estimated knee-heel growth velocity using different observation periods and measuring intervals is shown in Table 1.

In the study of the metal phantom, there was no correlation between the readings in a series. The technical error $(\sigma)$ was 0.12 $\mathrm{mm}$ and the error on one measurement $0.05 \mathrm{~mm}(\sigma / \sqrt{5})$.

Growth study of healthy preterm infants. Estimated from the 256 measurements of the 11 preterm infants, the variance $\left(\sigma^{2}\right)$ in this study was $0.96 \mathrm{~mm}^{2}$, but the study design did not allow us to estimate the covariance $\left(\tau^{2}\right)$. Growth curves (knee-heel length and weight) for the four infants with the longest period until RBW and for two infants representing those with a short 
Table 1. Standard error (SE) and coefficient of variation (CV) on determination of growth velocity using different measuring strategies*

\begin{tabular}{|c|c|c|c|c|c|c|c|c|c|c|}
\hline \multirow[b]{3}{*}{$\begin{array}{l}\text { Observation } \\
\text { period (d) }\end{array}$} & \multicolumn{10}{|c|}{ Frequency of knee-heel measurements } \\
\hline & \multicolumn{2}{|c|}{ First and last day } & \multicolumn{2}{|c|}{ Once weekly } & \multicolumn{2}{|c|}{$\begin{array}{l}\text { Three times a } \\
\text { week }\end{array}$} & \multicolumn{2}{|c|}{$\begin{array}{c}\text { First, second, last } \\
\text { but one, and last } \\
\text { day }\end{array}$} & \multicolumn{2}{|c|}{ Daily } \\
\hline & $\begin{array}{c}\mathrm{SE} \\
(\mathrm{mm} / \mathrm{d})\end{array}$ & $\begin{array}{l}\mathrm{CV} \\
(\%)\end{array}$ & $\begin{array}{c}\mathrm{SE} \\
(\mathrm{mm} / \mathrm{d})\end{array}$ & $\begin{array}{l}\mathrm{CV} \\
(\%)\end{array}$ & $\begin{array}{c}\mathrm{SE} \\
(\mathrm{mm} / \mathrm{d})\end{array}$ & $\begin{array}{l}\mathrm{CV} \\
(\%)\end{array}$ & $\begin{array}{c}\mathrm{SE} \\
(\mathrm{mm} / \mathrm{d})\end{array}$ & $\begin{array}{l}\mathrm{CV} \\
(\%)\end{array}$ & $\begin{array}{c}\mathrm{SE} \\
(\mathrm{mm} / \mathrm{d})\end{array}$ & $\begin{array}{l}\mathrm{CV} \\
(\%)\end{array}$ \\
\hline 8 & 0.17 & 34 & 0.17 & 34 & 0.16 & 32 & 0.14 & 28 & 0.13 & 26 \\
\hline 15 & 0.09 & 18 & 0.09 & 18 & 0.07 & 14 & 0.06 & 12 & 0.05 & 10 \\
\hline 22 & 0.06 & 12 & 0.05 & 10 & 0.04 & 8 & 0.04 & 8 & 0.03 & 6 \\
\hline 29 & 0.04 & 8 & 0.04 & 8 & 0.03 & 6 & 0.03 & 6 & 0.02 & 4 \\
\hline
\end{tabular}

* The coefficient of variation is calculated assuming a knee-heel growth velocity of $0.5 \mathrm{~mm} / \mathrm{d}$.
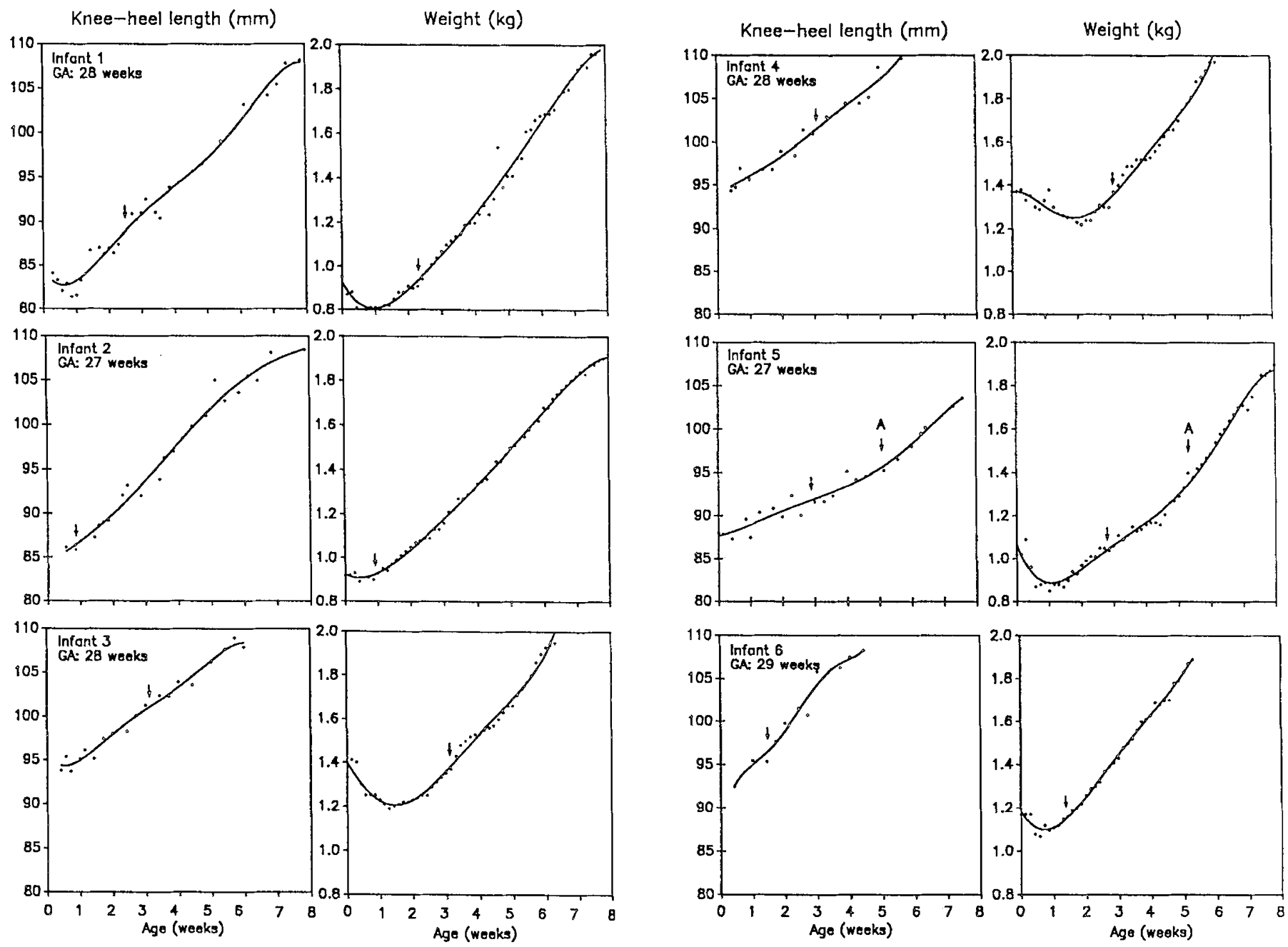

Fig. 2. Growth curves for six preterm infants without severe disease. The curves have been smoothed out using a 5 th degree polynomial. The age when birth weight was regained is shown with an arrow. $A$ indicates the age when infant 5 reached an oral intake of $180 \mathrm{~mL} / \mathrm{kg}$. $G A$, gestational age.

period until RBW are shown in Figure 2. For the four infants with a long period until RBW (nos. 1, 3, 4, and 5), the knee-heel length growth velocities and the weight gain were calculated both for the period from birth until RBW and from RBW until $21 \mathrm{~d}$ later (Table 2). The differences between the knee-heel velocities before and after RBW were not significantly different for any of the four infants (likelihood ratio test).

To compare knee-heel growth velocity and weight velocity during a period from RBW, velocities were calculated for each of the 11 infants for a 3-wk period from RBW. The mean velocities $( \pm \mathrm{SD}$ ) were $0.47 \pm 0.10 \mathrm{~mm} / \mathrm{d}$ and $24.7 \pm 4.3 \mathrm{~g} / \mathrm{d}$, respectively. The correlation between knee-heel growth velocity and weight velocity was significant $(p=0.02)$, but only $49 \%$ of the variation in knee-heel growth velocity between the infants could be explained by the differences in weight velocity.

To make a rough estimate of the day-to-day variation in kneeheel length, the variation of the individual measurements around the growth curve was calculated for each infant during the 3-wk period from RBW. The median value of the variation was 0.91 $\mathrm{mm}$ (range $(0.64-1.22 \mathrm{~mm}$ ). 
Table 2. Knee-heel length and weight velocities from birth to RBW and from $R B W$ until 21 d later in four preterm infants who did not regain birth weight during first 2 wk of life

\begin{tabular}{|c|c|c|c|c|c|c|}
\hline \multirow[b]{2}{*}{$\begin{array}{c}\text { Infant } \\
\text { no. }\end{array}$} & \multirow{2}{*}{$\begin{array}{c}\text { Gestational } \\
\text { age } \\
\text { (wk) }\end{array}$} & \multirow{2}{*}{$\begin{array}{l}\text { Age at } \\
\text { RBW } \\
\text { (d) }\end{array}$} & \multicolumn{2}{|c|}{ Knee-heel growth velocity* } & \multicolumn{2}{|c|}{ Weight velocity* } \\
\hline & & & $\begin{array}{l}\text { Birth-RBW } \\
(\mathrm{mm} / \mathrm{d})\end{array}$ & $\begin{array}{c}R B W+21 d \\
(\mathrm{~mm} / \mathrm{d})\end{array}$ & $\begin{array}{l}\text { Birth-RBW } \\
(\mathrm{g} / \mathrm{d})\end{array}$ & $\begin{array}{c}R B W+21 d \\
(g / d)\end{array}$ \\
\hline 1 & 28 & 17 & $0.41 \pm 0.07(15)$ & $0.44 \pm 0.05(11)$ & 0 & $26.7 \pm 1.5(22)$ \\
\hline 3 & 28 & 20 & $0.35 \pm 0.05(10)$ & $0.37 \pm 0.03(10)$ & 0 & $24.5 \pm 0.9(22)$ \\
\hline 4 & 28 & 22 & $0.35 \pm 0.05(10)$ & $0.49 \pm 0.05(9)$ & 0 & $27.1 \pm 1.0(22)$ \\
\hline 5 & 27 & 17 & $0.26 \pm 0.06(9)$ & $0.29 \pm 0.04(9)$ & 0 & $16.9 \pm 1.0(22)$ \\
\hline
\end{tabular}

* Values are means $\pm \mathrm{SD}$ (number of measurements).

\section{DISCUSSION}

We have shown that it is possible to measure knee-heel length with an error equivalent to less than $2 \mathrm{~d}$ growth in a preterm infant and thereby to measure linear growth velocity over periods down to a few weeks with an accuracy that makes it a useful parameter in growth studies.

To assess the reliability of an anthropometric measure, two different approaches, analysis of differences and analysis of variance, are commonly used (13). Analysis of differences is used to establish the repeatability, in some studies called the technical error. This is usually calculated using the difference between two independent measurements, either taken by the same observer on the same subject or by two different observers on the same subject. From these data the technical error of the measurement can be calculated using the formula $\sqrt{\Sigma \mathrm{d}^{2} / 2 \mathrm{k}}$, where d denotes the differences and $\mathrm{k}$ the number of comparisons. A slightly different approach has been used in assessing the reliability of knemometry in older children $(4,5)$. In those studies, one observer took six sequential readings on one child and the technical error was calculated as the SD within a series using a similar formula (4). If the technical error is regarded as an estimate of the total error, it must be assumed that each of the readings in a series is completely independent, i.e. that the readings within a series are not correlated. This is not always the case and thus several elements of error are not included in the technical error. One observer might have a bias that varies from child to child. Different observers might have a constant personal bias and one observer might have a different bias on different days. If the same observer has to read several values in a series, there is also a risk that he will tend to select values that resemble the previous values. It is possible to estimate these elements of error through an analysis of absolute values using the analysis of variance procedure, which was the method used in the present study.

Two significant sources of error, $\sigma$ and $\tau$, were identified in this study. Assuming that there were no other error components than $\sigma$, the technical error of one measurement (mean of five readings) would be $0.55 \mathrm{~mm}\left(\sqrt{\sigma^{2} / 5}\right)$. However, this figure is too low because of a positive correlation between the readings in a series, which increases the total error of a measurement to 0.82 $\mathrm{mm}$. This correlation component, which includes the withinobserver and between-observer variation, is due to an error caused by an interaction between the observer and the infant. It might be caused by differences between each measurement in the way the observer measures the infant or by differences in the way the infant reacts to being measured, such as differences in the degree to which the infant is relaxed.

The error found when measuring the metal phantom was in the same magnitude as the errors reported using the large knemometer $(4,5)$. The reasons for the considerably larger error found when measuring infants are less stability in the ankle joint, making it sensitive to deformation, and difficulties in placing the lower leg in exactly the same way during each reading, partly because the infant does not cooperate. The larger error is, how- ever, compensated by the very high linear growth velocity in newborn infants.

The error described in the present study might change under different circumstances. $\sigma$ was less in the preterm growth study, during which the observers had more experience, than during the reliability study. If the number of readings in a measurement is increased, the contribution from $\sigma$ to the total error is reduced by the square root of the number of readings. As an example, in the preterm growth study, in which $\sigma^{2}$ was $0.96 \mathrm{~mm}^{2}$ and $\tau^{2}$ was assumed to be the same as in the reliability study, the standard error of one measurement would decrease from 0.75 to $0.68 \mathrm{~mm}$ if the number of readings increased from five to 10 . If a measurement only consisted of one reading, the error would be 1.03 mm.

Although we found no systematic differences between the lengths measured by the two observers in the reliability study, it is our impression that different observers, especially when inexperienced, might measure with a systematic difference. If several observers are measuring the same infant in a growth study, their measurements should be compared in a reliability study before the start of the study.

The method used in this study to estimate day-to-day variation in knee-heel length in the growth study of preterm infants includes both the true day-to-day variation not caused by growth, the total error of the measurement, and any deviation in true growth from a rectilinear pattern. We can, therefore, only conclude that the SD of the true day-to-day variation is less than the $0.9 \mathrm{~mm}$ found in this study. This figure is close to the corresponding SD of $0.7 \mathrm{~mm}$ found when using the large knemometer (4), but in preterm infants this day-to-day variation is only equivalent to $\sim 2 \mathrm{~d}$ of knee-heel growth, whereas in preschool children it corresponds to $\sim 2 \mathrm{wk}$ of knee-heel growth. If knee-heel measurements are used to calculate growth velocities, any day-to-day variation in excess of rectilinear growth must be regarded as noise and therefore an additional error component, even if it might be caused by minor fluctuations in true growth velocity.

The main reason for measuring knee-heel length is to calculate short-term growth velocity, and the error of measuring growth velocity is therefore of interest. The error is dependent on the study period and the frequency of measurement (Table 2). If the observation period is defined from the start of the study and it is decided to measure velocity over the period by linear regression, a strategy of measuring for a few days at the start and at the end of the period is more efficient than frequent measurements throughout the study period. If it is also of interest to describe the growth pattern during the period, frequent measurements are necessary, e.g. three times weekly, as in the present study of preterm infants.

There are differences between the knee-heel and the weight growth pattern in preterm infants. In this study, linear growth velocity was rather constant right from birth and did not show the same deceleration as weight, which agrees with a recent study on linear growth in the early neonatal period (14). Furthermore, only $49 \%$ of the variation between the individual infants in kneeheel growth velocity during the 3-wk period after RBW could be 
explained by differences in weight velocity during the same period.

Weight velocity is often used as the major short-term outcome in nutritional studies of preterm infants, but it might not always reflect true growth because of changes in hydration and fat deposition. Linear growth velocity is a better indicator of true growth, and we therefore suggest that in growth studies of preterm infants linear growth velocity, based on knee-heel length measurements, should be used as a major short-term outcome.

The method is also valuable in measuring the progress of ill infants, in whom fluctuations in weight, due to fluid retention and dehydration, are common. The method is less disturbing to the infant than measuring the total length and can easily be used on severely ill infants, such as infants on artificial ventilation.

Acknowledgments. The authors thank Jan Sommer and Allan Northeved, who were very innovative in developing the knemometer.

\section{REFERENCES}

1. Babson SG, Bramhall JL 1969 Diet and growth in the premature infant. J Pediatr 74:890-900

2. Gaull GE, Rassin DK, Rih NCR 1977 Protein intake of premature infants: a reply. J Pediatr 90:507-510

3. Valk IM, Chabloz MEL, Smals AGH, Kloppenborg PWC, Cassorla FG,
Schutte AAST 1983 Accurate measurements of the lower leg length and the ulnar length and its application in short term growth measurement. Growth $47: 53-66$

4. Hermanussen M, Geiger-Benoit K, Burmeister J, Sippell WS 1988 Knemometry in childhood: accuracy and standardization of a new technique of lower leg length measurement. Ann Hum Biol 15:1-16

5. Wit JM, Karlsbeek JM, Wijk-Hoek JM, Leppink GJ 1987 Assessment of the usefulness of weekly knemometric measurements in growth studies. Acta Paediatr Scand 76:974-980

6. Wales JKH, Milner RDG 1987 Knemometry in assessment of linear growth. Arch Dis Child 62:166-171

7. Michaelsen KF, Mortensen HB, Skakkebæk NE 1988 A new knemometer for assessing linear growth. Pediatr Res 24:528(abstr)

8. Cronk CE, Stallings VA, Spender QW, Ross JL, Widdoes HD 1989 Measurement of short term growth with a new knee height measuring device (KHMD). Am J Hum Biol 1:421-428

9. Mortensen HB, Main K, Michaelsen KF, Kastrup KW, Jørgensen JT, Skakkebæk NE 1991 Predicting and monitoring of growth in children with short stature during the first year of growth hormone treatment. Acta Paediatr Scand (in press)

10. Brooke OG, Alvear J, Arnold M 1979 Energy retention, energy expenditure, and growth in healthy immature infants. Pediatr Res 13:215-220

11. Brooke OG, Onubogu O, Heath R, Carter ND 1987 Human milk and preterm formula compared for effects of growth and metabolism. Arch Dis Child 62:917-923

12. Winer BJ 1971 Statistical Principles in Experimental Design, 2nd Ed. McGrawHill, New York

13. Cameron $\mathrm{N} 1986$ The methods of auxological anthropometry. In: Falkner F, Tanner JM (eds) Human Growth, Vol III. Plenum Press, New York, pp $3-$ 46

14. Bishop NJ, King FJ, Lucas A 1990 Linear growth in the early neonatal period. Arch Dis Child 65:707-708 